\title{
Characterisation of Pseudomonas lundensis CP-P-5 as a potential antagonist of foodborne pathogenic bacteria
}

\author{
B. Baráti-Deák, Á. Belák* (1) and Cs. Mohácsi-Farkas
}

Department of Microbiology and Biotechnology, Faculty of Food Science, Szent István University, Somlói út 14-16, H-1118 Budapest, Hungary

\section{ORIGINAL RESEARCH PAPER}

\section{ABSTRACT}

Previously isolated Pseudomonas lundensis CP-P-5 had antagonistic activity against Salmonella Hartford, Yersinia enterocolitica, and Escherichia coli. In this study, determination of its antagonistic mechanism and potential field of application in food industry was aimed. Using cellophane-test and microcultures of the test strain's cell-free supernatant mixed with the pathogens, our results showed that cells of $P$. lundensis CP-P-5 and its concentrated cell-free supernatants were effective against the foodborne bacteria, and the supernatants contained more than one compound responsible for inhibitory activity. Searching for the antagonistic compound, $\mathrm{NaOH}$, protease, and heat treatments were done to the supernatants, and proteolytic activity and siderophore production were also tested using the antagonistic strain. Our results support the potential applicability of $P$. lundensis CP-P-5 as a bioprotective agent against foodborne pathogens in food processing environments.

\section{KEYWORDS}

bioprotective agent, foodborne pathogens, biocontrol, P. lundensis, S. Hartford, Y. enterocolitica, E. coli

*Corresponding author. E-mail: Belak.Agnes@uni-mate.hu 


\section{INTRODUCTION}

Food safety has a worldwide importance as different foodborne pathogenic microorganisms threaten our health when consuming contaminated or poorly preserved food products. In the European Union, the reported number of human cases, hospitalisations, and deaths due to zoonoses in 2018 were 359,692, 41,203, and 572, respectively (EFSA, 2019), but the real numbers are likely to be much higher.

Relatively new physical technologies (e.g. ionising radiation, high hydrostatic pressure HHP, or pulsed electric field - PEF) can be used for ensuring safety of foods. Biocontrol can also be an alternate preservation method, and it can be part of a hurdle technology (Farkas, 2001) or sometimes it could replace the traditional preservation techniques.

Pseudomonas species are considered effective biocontrol agents of soilborne (Weller, 2007) as well as foodborne pathogenic bacteria (Alegre et al., 2013). Scientific publications demonstrate that isolates of the genus Pseudomonas - mainly fluorescent pseudomonads - have antagonistic ability against different foodborne pathogens (Alegre et al., 2013; Olanya et al., 2014; Belák \& Maráz, 2015; Oliveira et al., 2015). Secondary metabolites of fluorescent Pseudomonas species, such as phenazines (PHZ), 2,4-diacetylphloroglucinol (DAPG), pyoluteorin (PLT), pyoverdine (pseudobactin), pyrrolnitrin (PRN), cyclic lipopeptides (CLPs), indoleacetate, and volatile organic compounds (VOCs), such as hydrogen cyanide ( $\mathrm{HCN})$, play important role in their biocontrol activity. These metabolites have antifungal, antibacterial, antiviral, antitumor, and anti-nematicidal properties (Haas et al., 1991; Mishra \& Arora, 2018).

In our previous study, bacteria with antagonistic activity were isolated from various food processing environments (Baráti-Deák et al., 2020). One of the most effective isolates against the tested pathogens proved to be Pseudomonas lundensis CP-P-5. In this study this bacterium was characterised and tested to determine its antagonistic mechanism and potential field of application in the food industry.

\section{MATERIALS AND METHODS}

\subsection{Bacterial strains tested and their maintenance}

Pathogenic bacteria used for testing the inhibitory effect of $P$. lundensis CP-P-5 (antagonistic bacterial strain) were the followings: Salmonella Hartford (NCAIM B1310, National Collection of Agricultural and Industrial Microorganisms, Budapest, Hungary), Yersinia enterocolitica (HNCMB 98002, Hungarian National Collection of Medical Bacteria, Budapest, Hungary), and Escherichia coli (NCAIM B01909, National Collection of Agricultural and Industrial Microorganisms, Budapest, Hungary). All strains were maintained on TSA (Biokar Diagnostics, Cedex, France) slants at $4{ }^{\circ} \mathrm{C}$.

\subsection{Contact inhibition test using agar plates with different $\mathrm{pH}$ values}

These tests were done with all pathogens, using spot method described in the paper of BarátiDeák et al. (2020). To obtain agar with different $\mathrm{pH}$ values $(\mathrm{pH} \mathrm{4,} \mathrm{5,} \mathrm{6,} \mathrm{7,} \mathrm{8,} \mathrm{and} \mathrm{9)} \mathrm{TSA} \mathrm{plates}$ were made using different buffers as described in our previous study (Baráti-Deák et al., 2020). The incubation temperatures were 20 and $30{ }^{\circ} \mathrm{C}$, respectively, and the incubation time was $24 \mathrm{~h}$ at both temperatures. The tests were done in duplicates. 


\subsection{Testing the inhibitory ability of $P$. lundensis CP-P-5 by cellophane test}

The analysis was made according to Giolitti and Bertani (1952) with some minor modifications. Small cellophane (Hewa, Sarantis Hungary Ltd., Budaörs, Hungary) disks with approximately $4 \mathrm{~cm}$ diameter were cut and placed in a glass petri dish using filter paper to separate them. The filter papers were previously soaked in distilled water, and the cellophane disks were carefully put on the wet paper. After autoclaving, the cellophanes were placed onto TSA plates together with the filter paper using sterile forceps, which, therefore, was able to minimalise the chance of air bubbles appearing under the cellophane. The filter paper was then removed and $10 \mu \mathrm{l}$ of the antagonistic strain (approx. $10^{8}-10^{9} \mathrm{CFU} \mathrm{mL}{ }^{-1}$ ) was dropped onto the cellophane disks. After $24 \mathrm{~h}$ of incubation at $25{ }^{\circ} \mathrm{C}$, the cellophane - which contained the colonies on its surface - was removed using sterile forceps. The inoculation of these TSA plates with the pathogenic bacteria - after removing the cellophane - was the same as described at the screening method in our previous study (Baráti-Deák et al., 2020).

\subsection{Inhibitory effect of cell-free supernatants of $P$. Iundensis CP-P-5 generated by different culturing conditions}

Inhibitory assays using cell-free supernatants of static and shake-flask (180 r.p.m.) TSB (Biokar Diagnostics, Cedex, France) and peptone-glucose-yeast extract (PGY, Biokar Diagnostics, Cedex, France) cultures were made as described in Baráti-Deák et al. (2020) to determine the optimal conditions for production of the antagonistic compound(s). The incubation temperature was $25^{\circ} \mathrm{C}$, and samples were taken on the first, the third, and the sixth days of incubation. The flasks were duplicated.

\subsection{Production of concentrated cell-free supernatant by lyophilisation}

To get more concentrated supernatants of $P$. lundensis CP-P-5, the one-, three-, and six-day-old cell-free supernatants generated from cultures in TSB were frozen at $-80{ }^{\circ} \mathrm{C}$, then lyophilised (ScanVac CoolSafe ${ }^{\mathrm{TM}}$, Labogene, Allerød, Denmark) and soaked in one-tenth amount of TSB. Therefore, a ten times more concentrated supernatant was used for further tests. The inhibition assays were repeated with this concentrated supernatant using Multiscan Ascent photometer (Thermo Fisher Scientific, Waltham, Massachusetts, USA) as described by Baráti-Deák et al. (2020).

\subsection{Protease, $\mathrm{NaOH}$, and heat treatments of the cell-free supernatants}

24-h-old cell-free supernatants of static TSB cultures and the concentrated supernatants were treated with the followings to obtain more information of the antagonistic compound: (i) protease treatment by one of the following: proteinase K (Sigma-Aldrich, St. Louis, MO, USA) $200 \mu \mathrm{g} \mathrm{mL}^{-1}$, protease from Streptomyces griseus (Sigma-Aldrich, St. Louis, MO, USA) $200 \mu \mathrm{g} \mathrm{mL}^{-1}$, trypsin from bovine pancreas (Sigma-Aldrich, St. Louis, MO, USA) $100 \mu \mathrm{g} \mathrm{mL}^{-1}$, and $\alpha$-chymotrypsin from bovine pancreas (Sigma-Aldrich, St. Louis, MO, USA) $100 \mu \mathrm{g} \mathrm{mL}{ }^{-1}$, at $37^{\circ} \mathrm{C}$ for $90 \mathrm{~min}$, (ii) $0.2 \mathrm{~N} \mathrm{NaOH}$ treatment, and (iii) heat treatment at $95^{\circ} \mathrm{C}$ for $5 \mathrm{~min}$ and $30 \mathrm{~min}$, or at $121^{\circ} \mathrm{C}$ for $15 \mathrm{~min}$. The treated supernatants were used against Salmonella Hartford NCAIM B1310 observing its growth using Multiscan Ascent (Thermo Fisher Scientific, Waltham, Massachusetts, USA) with the method described previously (Baráti-Deák et al., 2020). 


\subsection{Analysis of siderophore production}

Siderophore production was tested using CAS agar plates according to Schwyn and Neilands (1986) and Verma et al. (2012) with the modification of the base medium. The CAS plates were made using 900 mL Kings B (Merck, Darmstadt, Germany) mixed with the dye containing 60.5 $\mathrm{mg}$ chromeazurol-S (Sigma-Aldrich, St. Louis, MO, USA) dissolved in $50 \mathrm{~mL}$ water and mixed with $10 \mathrm{~mL}$ iron (III) Solution ( $1 \mathrm{mM} \mathrm{FeCl}_{3} \cdot 6 \mathrm{H}_{2} \mathrm{O}$ and $\left.10 \mathrm{mM} \mathrm{HCl}\right)$. During stirring, the solution was added to $72.9 \mathrm{mg}$ HDTMA (hexadecyltrimethylammonium bromide, SigmaAldrich, St. Louis, MO, USA), which was previously dissolved in $40 \mathrm{~mL}$ water. The base medium and the CAS dye were autoclaved separately and mixed before usage. The CAS agar plates were inoculated with the overnight culture of $P$. lundensis CP-P-5 and incubated for $24 \mathrm{~h}$ at $25{ }^{\circ} \mathrm{C}$.

\subsection{Testing of proteolytic activity of $P$. lundensis CP-P-5}

Protease activity of the antagonistic strain was tested using skim milk agar (SMA) (yeast $2.5 \mathrm{~g} \mathrm{~L}^{-1}$, peptone $1 \mathrm{~g} \mathrm{~L}^{-1}$, glucose $5 \mathrm{~g} \mathrm{~L}^{-1}$, milk powder $10 \mathrm{~g} \mathrm{~L}^{-1}$, and agar $15 \mathrm{~g} \mathrm{~L}^{-1}$ ). A loopful of overnight culture was put in $0.5 \mathrm{~mL}$ sterile water and mixed vigorously. Ten microlitres of the suspension was dropped onto the surface of SMA. The plates were then incubated at 20, 25, or $30{ }^{\circ} \mathrm{C}$. The appearing clearing zones were measured and checked after one, two, and five days of incubation. The test was done in triplicates.

\subsection{Statistical analysis}

Standard deviation of the collected data was calculated using Microsoft Excel's STDEV function.

\section{RESULTS AND DISCUSSION}

Based on previous results, $P$. lundensis CP-P-5 was chosen for further analyses, as this strain showed strong antagonistic effect on three tested pathogens ( $S$. Hardford, Y. enterocolitica, and E. coli) by contact inhibition tests (Baráti-Deák et al., 2020). Furthermore, it was not able to grow at 37 and $42{ }^{\circ} \mathrm{C}$ - human and animal pathogens usually propagate well at these higher temperatures - and the optimum was between 20 and $30{ }^{\circ} \mathrm{C}$, which overlaps the most effective inhibition temperature range of the above-mentioned pathogens.

To observe whether the $\mathrm{pH}$ has any effect on the inhibitory property of $\mathrm{P}$. lundensis $\mathrm{CP}-\mathrm{P}-5$ against the tested foodborne pathogenic bacteria, contact inhibition tests (agar spot method) using agar plates with different $\mathrm{pH}$ values were done. The results showed that in case of $S$. Hartford and E. coli, the lower $\mathrm{pH}$ values $(4,5$, and 6$)$ combined with lower temperature $\left(20^{\circ} \mathrm{C}\right)$ had stronger inhibitory effect on the growth of the pathogens. At higher $\mathrm{pH}$ values and temperature $\left(30^{\circ} \mathrm{C}\right)-$ which are closer to the optimal for the pathogens - the growth inhibition was only partial. In case of $Y$. enterocolitica, low $\mathrm{pH}(4,5$, and 6$)$ and temperature $\left(20^{\circ} \mathrm{C}\right)$ proved to be enough to inhibit its growth, as the pathogen was not able to grow in itself on the positive control. At $30^{\circ} \mathrm{C}$ and with higher $\mathrm{pH}(7,8$, and 9), inhibition of $Y$. enterocolitica was only partial as well. These results highlight the importance of unfavourable environmental parameters for growth inhibition of pathogenic bacteria and the additive effect of ecological parameters and biocontrol metabolites.

Before further analysis of the inhibitory compound(s), cellophane test was performed for determining whether the metabolite(s) derived from the antagonistic strain could inhibit the 
pathogens without the presence of its cells. It was important, as cell-free supernatants of the antagonistic strains were not as effective in growth inhibition as the cells in co-culturing study (Baráti-Deák et al., 2020). After the incubation time, visible clearing zones of the pathogens were observed on those points of the agar, where the cellophane was previously placed, and the bacterium cells were cultured (Fig. 1). This means that P. lundensis CP-P-5 produced the inhibitory compound(s) during its cultivation without the presence of the inhibited pathogen, and the metabolites were able to diffuse into the agar through the cellophane layer. It supports the presumption that the inhibitory compounds are extracellular substances and could be primary metabolites of the producing strain.

As the cell-free supernatants of the isolated antagonistic strains did not show as effective inhibition as it was seen in co-culturing study, different circumstances using TS and PGY broth under static or shaking culturing conditions were tested in case of P. lundensis CP-P-5. Our results showed that neither PGY broth nor shaking conditions had any positive effect on the inhibitory compound production of the strain. Furthermore, the previously seen antagonistic activity was weakened as a cause of change in parameters of culturing conditions. The best inhibitory effect was seen using TS broth under static condition.

As our results generated by agar spot method refers to the fact that the inhibitory compounds have better effect if they are present in more concentrated form, lyophilisation of cellfree supernatant (generated from static TSB culture) of P. lundensis CP-P-5 was done. The results proved that the ten times concentrated supernatant had stronger antagonistic effect against all three tested pathogens. Moreover, the best inhibitory effect was detected with supernatants obtained from 24 hour-old culture broth of the strain, while the three- and six-dayold lyophilised supernatants were not as effective as the one-day-old.

Neither protease nor $\mathrm{NaOH}$ treatments of non-concentrated cell-free supernatants generated in TSB under static conditions affected their slight inhibitory effect on the tested pathogens, however, after heat treatments, there was no inhibition observed. It may refer to the fact that the inhibitory compound is heat sensitive and resistant to the applied proteolytic enzymes. In

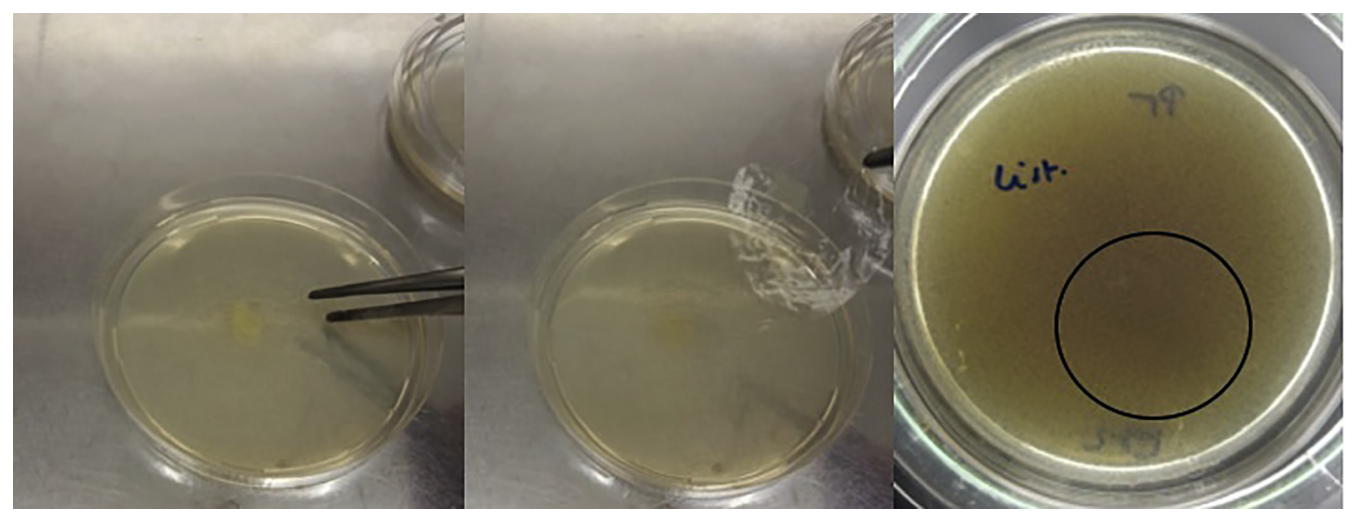

Fig. 1. Cellophane test with P. lundensis CP-P-5 strain and its partial inhibition against L. monocytogenes (first and second pictures: cellophane removal after $24 \mathrm{~h}$ of incubation with P. lundensis CP-P-5 on it, third picture: mild clearing zone - where previously the test strain grew on the cellophane - after $24 \mathrm{~h}$ of incubation with the pathogen) 
contrast with these results, the enzymatic treatments of the lyophilised supernatants showed that protease from $S$. griseus and proteinase $\mathrm{K}$ could decrease the antagonistic effect of the concentrated supernatants on $S$. Hartford, while the other treatments $(\mathrm{NaOH}$, heat treatments, trypsin, and $\alpha$-chymotrypsin) did not affect them. In case of E. coli, the antagonistic effect of supernatants decreased after some of the treatments (the $\mathrm{NaOH}$ treatment had the highest impact on the supernatants), while the protease from S. griseus and $\alpha$-chymotrypsin did not influence their antagonistic activities. In case of Y. enterocolitica, none of the treatments had any effect on the growth inhibitory effect of the cell-free supernatants, however, this pathogen was the most sensitive in each examination (Table 1).

Summarising these results, it can be said that in the non-concentrated supernatants, the substrates of the proteolytic enzymes might have been in low concentrations, that is why in these cases there were no changes in the inhibitory pattern. At the same time, in the ten-times concentrated samples, the metabolites were enriched and proved to be present in sufficient concentration for enzymatic break-down. As it can be seen from Table 1, significantly different results were generated by the enzymatic, heat, and $\mathrm{NaOH}$ treatments, which could refer to the fact that more than one inhibitory compounds were responsible for the growth decline of the pathogens, and, in addition, various metabolites have impact on the different pathogenic bacteria.

Siderophore production of $P$. lundensis CP-P-5 was tested using CAS agar. The occurring orange clearing zone on the blue agar meant that the strain could produce chelating metabolite (Fig. 2). Proteolytic activity was also confirmed in case of this strain, as at all three tested temperatures clearing zones were observed on SMA plates. The size of the zones increased significantly during the $72 \mathrm{~h}$ of incubation, and the best proteolytic activity was observed at $25^{\circ} \mathrm{C}$ (Table 2). As in case of P. lundensis CP-P-5, the best antagonistic activity was observed at $25{ }^{\circ} \mathrm{C}$, there could be correlation between the inhibitory effect and the ability of protease production of this strain.

Application of biocontrol agents can be the solution for eliminating foodborne pathogens. Leverentz et al. (2006) found four antagonists (one bacterium and three yeast strains), which were effective in preventing the growth or survival of foodborne human pathogens on fresh-cut

Table 1. Effects of enzyme, heat, and alkaline treatments on antagonistic activity of supernatants derived from $P$. lundensis CP-P-5 (number of observations, $n=3$ )

\begin{tabular}{|c|c|c|c|c|}
\hline \multirow[b]{2}{*}{$\begin{array}{l}\text { Treatment of the cell free } \\
\text { supernatant }\end{array}$} & \multirow{2}{*}{$\begin{array}{l}\text { Supernatant of } \\
\text { CP-P-5 } \\
\text { Salmonella Hartford }\end{array}$} & \multicolumn{3}{|c|}{$10 \times$ concentrated supernatant of CP-P-5 } \\
\hline & & $\begin{array}{c}\text { Salmonella } \\
\text { Hartford }\end{array}$ & E. coli & Y. enterocolitica \\
\hline Proteinase $\mathrm{K}$ & - & + & + & - \\
\hline Protease & - & + & - & - \\
\hline Trypsin & - & - & + & - \\
\hline$\alpha$-Chymotrypsin & - & - & - & - \\
\hline $0.2 \mathrm{~N} \mathrm{NaOH}$ & - & - & + & - \\
\hline $95{ }^{\circ} \mathrm{C}$ for $15 \mathrm{~min}$ & + & - & + & - \\
\hline $95^{\circ} \mathrm{C}$ for $30 \mathrm{~min}$ & + & - & - & - \\
\hline $121{ }^{\circ} \mathrm{C}$ for $15 \mathrm{~min}$ & + & - & - & - \\
\hline
\end{tabular}

+: The enzyme or treatment reduced the antagonistic effect.

$-:$ The enzyme or treatment did not affect the antagonistic effect. 


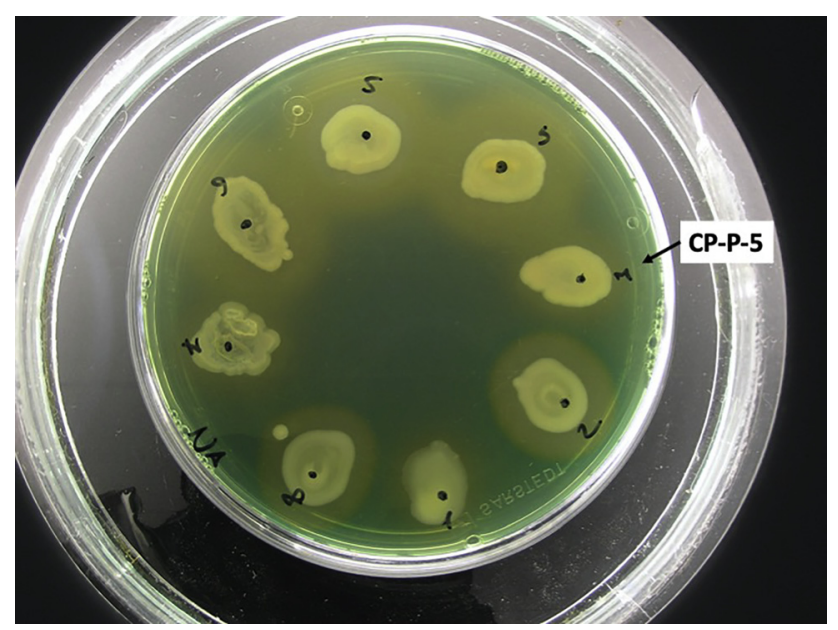

Fig. 2. Siderophore activity of P. lundensis CP-P-5 strain on CAS agar after incubation at $25{ }^{\circ} \mathrm{C}$ for $24 \mathrm{~h}$

apple tissue. All antagonists were originally isolated from apple surfaces. In another study, biopreservative bacterial strain CPA- 6 belonging to the family Enterobacteriaceae and isolated from minimally processed (MP) apples was able to control a non-pathogenic strain of $E$. coli O157:H7, Salmonella, and Listeria innocua on MP apple and peach (Alegre et al., 2012). Alegre et al. (2013) isolated Pseudomonas graminis CPA-7 from fruit, which could inhibit the growth of some foodborne pathogenic bacteria on fresh-cut apple and peach. Biocontrol can also be used as an alternative disinfection practice. A surface sanitiser comprising three lactic acid bacteria (Carnobacterium maltaromaticum, C. maltaromaticum, and Enterococcus mundtii) together with nisin for the control of L. monocytogenes was patented (Twele et al., 2011). Furthermore, Schöbitz et al. (2014) formulated and designed a biocontroller for application in the food processing environment and evaluated its inhibitory capacity against biofilms of L. monocytogenes grown in floor gutters in a salmon processing plant.

Many Pseudomonas species can be biocontrol and growth-promoting agents, as they can grow rapidly in vitro and generate biomass, they are able to produce a wide spectrum of bioactive metabolites (i.e. antibiotics, siderophores, volatiles, and growth-promoting substances), they may compete aggressively with other microorganisms, and they can adapt to environmental stresses (Weller, 2007). In previous studies, Pseudomonas strains with antagonistic effect on

Table 2. Proteolytic activity of $P$. lundensis CP-P-5 using skim milk agar for the detection of clearing zones $(\text { diameter, } \mathrm{mm})^{*}$

\begin{tabular}{lccc}
\hline & \multicolumn{3}{c}{ Incubation time } \\
\cline { 2 - 4 } Incubation temperature & $24 \mathrm{~h}$ & $48 \mathrm{~h}$ & $120 \mathrm{~h}$ \\
\hline $20^{\circ} \mathrm{C}$ & $3.33 \pm 0.236$ & $6.17 \pm 0.236$ & $17.67 \pm 0.236$ \\
$25{ }^{\circ} \mathrm{C}$ & $4 \pm 0$ & $7.33 \pm 0.236$ & $15.17 \pm 0.236$ \\
$30^{\circ} \mathrm{C}$ & $1.83 \pm 0.417$ & $6 \pm 0.707$ & $10 \pm 0$ \\
\hline
\end{tabular}

*: Values are means $\pm \mathrm{SD}$, based on three repetitions. 
foodborne pathogenic bacteria were isolated (Alegre et al., 2013; Olanya et al., 2014; Belák \& Maráz, 2015; Oliveira et al., 2015) and most of them were fluorescent pseudomonads. P. lundensis CP-P-5 can also produce fluorescent pigments on King B agar (data are not shown). As this strain was isolated from a surface of an abattoir, the application of P. lundensis CP-P-5 as a biocontrol strain can have a potential in the food industry. Till now we could not find any scientific publication in which antagonistic P. lundensis had been previously described.

\section{CONCLUSIONS}

P. lundensis CP-P-5 isolated from an abattoir was previously selected from potential antagonistic isolates, as it had the most promising inhibitory effect against the tested foodborne pathogenic bacteria. This strain was able to inhibit the growth of $S$. Hartford, Y. enterocolitica, and E. coli. Inhibitory ability of CP-P-5 was demonstrated in contact inhibition and micro-culturing tests as well. Both approaches showed that P. lundensis CP-P-5 can be a good candidate as biocontrol agent, however, as direct application of bacterial cells can lead to spoilage of food products, usage of compounds produced and excreted by the strain can be an alternative solution. Moreover, concentrated extracellular metabolites of $P$. lundensis CP-P-5 may also serve as biodisinfectants in food producing environments. However, further trials are needed to ensure that this strain is safe to use in food processing environments. To our best knowledge, this is the first study in which a $P$. lundensis strain was described as a potential antagonist of foodborne pathogenic bacteria, however, the characterisation of inhibitory compounds taking part in its antagonistic action has to be continued.

\section{ACKNOWLEDGEMENT}

This research was supported by the European Union and the State of Hungary, co-financed by the European Social Fund in the framework of TÁMOP 4.2.4. A/-11-1-2012-0001 'National Excellence Program' and the Doctoral School of Food Sciences (SZIU).

\section{REFERENCES}

Alegre, I., Viñas, I., Usall, J., Anguera, M., Figge, M.J., and Abadias, M. (2012). An Enterobacteriaceae species isolated from apples controls foodborne pathogens on fresh-cut apples and peaches. Postharvest Biology and Technology, 74: 118-124.

Alegre, I., Viñas, I., Usall, J., Teixidó, N., Figge. M.J., and Abadias, M. (2013). Control of foodborne pathogens on fresh-cut fruit by a novel strain of Pseudomonas graminis. Food Microbiology, 34(2): 390-399.

Baráti-Deák, B., Mohácsi-Farkas, Cs., and Belák, Á. (2020). Searching for antagonistic activity of bacterial isolates derived from food processing environments on some food-borne pathogenic bacteria. Acta Alimentaria, 49: 415-423.

Belák, Á. and Maráz, A. (2015). Antagonistic effect of Pseudomonas sp. CMI-1 on foodborne pathogenic Listeria monocytogenes. Food Technology \& Biotechnology, 53(2): 223-230. 
EFSA (2019). The European Union one health 2018 zoonoses report. EFSA Journal, 17(12): e05926.

Farkas, J. (2001). Future trends in food technology- novel food and transgenic food. Acta Alimentaria, 30: 267-279.

Giolitti, G. and Bertani, M. (1952). A method for the microscopical study of actinomycetes. Journal of Bacteriology, 65: 281-282.

Haas, D., Keel, C., Laville, J., Maurhofer, M., Oberhänsli, T., Schnider, U., Voisard, C., Wüthrich, B., and Defago, G. (1991). Secondary metabolites of Pseudomonas fluorescens strain CHA0 involved in the suppression of root diseases. In Hennecke, H. and Verma, D.P.S. (Eds.), Advances in molecular genetics of plant-microbe interactions, Vol. 1. Current plant science and biotechnology in agriculture 10. Springer, Dordrecht, pp. 450-456.

Leverentz, B., Conway, W.S., Janisiewicz, W., Abadias, M., Kurtzman, C.P., and Camp, M.J. (2006). Biocontrol of the food-borne pathogens Listeria monocytogenes and Salmonella enterica serovar Poona on fresh-cut apples with naturally occurring bacterial and yeast antagonists. Applied and Environmental Microbiology, 72(2): 1135-1140.

Mishra, J. and Arora, N.K. (2018). Secondary metabolites of fluorescent pseudomonads in biocontrol of phytopathogens for sustainable agriculture. Applied Soil Ecology, 125: 35-45.

Olanya, O.M., Ukuku, D.O., and Niemira, B.A. (2014). Effects of temperatures and storage time on resting populations of Escherichia coli O157:H7 and Pseudomonas fluorescens in vitro. Food Control, 39: 128-134.

Oliveira, M., Abadias, M., Colás-Medà, P., Usall, J., and Viñas, I. (2015). Biopreservative methods to control the growth of foodborne pathogens on fresh-cut lettuce. International Journal of Food Microbiology, 214: 4-11.

Schöbitz, R., González, C., Villarreal, K., Horzella, M., Nahuelquín, Y., and Fuentes, R. (2014). A biocontroller to eliminate Listeria monocytogenes from the food processing environment. Food Control, 36(1): 217-223.

Schwyn, B. and Neilands, J.B. (1986). Universal chemical assay for the detection and determination of siderophores. Analytical Biochemistry, 160(1): 47-56.

Twele, R.P.S., Panno, L.C., Lobo, M.E.C., Contreras, C.S.B., Perez, J.R.F., Rademacher, M.H., Rios, Y.I.N.R., and Hinostroza, C.d.C.V. (2011). Surface sanitizer for the food industry based on three new lactic acid bacteria that have antagonistic action against Listeria monocytogenes, the microorganism that causes listeriosis in humans. US Patent US8062633B2.

Verma, V., Joshi, K., and Mazumdar, B. (2012). Study of siderophore formation in nodule-forming bacterial species. Research Journal of Chemical Sciences, 2(11): 26-29.

Weller, D.M. (2007). Pseudomonas biocontrol agents of soilborne pathogens: looking back over 2 years. Phytopathology, 97(2): 250-256.

Open Access. This is an open-access article distributed under the terms of the Creative Commons Attribution 4.0 International License (https://creativecommons.org/licenses/by/4.0/), which permits unrestricted use, distribution, and reproduction in any medium, provided the original author and source are credited, a link to the CC License is provided, and changes - if any - are indicated. (SID_1) 